\title{
Development of a tool to assess children's knowledge of non-milk extrinsic sugars, general nutrition, energy balance and physical activity
}

\author{
T. Griffin ${ }^{1}$, J. Macdiarmid ${ }^{2}$, J. Loe ${ }^{2}$, D. Jackson ${ }^{2}$ and G. McNeill ${ }^{1,2}$ \\ ${ }^{1}$ Public Health Nutrition Research Group, University of Aberdeen, Aberdeen AB25 2ZP, UK and ${ }^{2}$ Rowett Institute of \\ Nutrition and Health, University of Aberdeen, Aberdeen AB21 9SB, UK
}

Children's intakes of non-milk extrinsic sugars (NMES) are considerably higher than the recommended intake of less than $10 \%$ of total energy $^{(1)}$, with a recent survey showing the average intake of NMES for children in Scotland being $17.4 \%$ of their food energy ${ }^{(2)}$. There is also increasing evidence to link intakes of NMES with weight gain ${ }^{(3)}$; however, little is known about children's current knowledge of NMES, physical activity and energy balance. The aim of this study was to design a questionnaire for children to assess their knowledge of these topics for use in an intervention. The questionnaire was developed in three stages with children aged 8-12 years and changes were made based on feedback from each stage. It was designed to appeal to children and teaspoons of sugar were used as a unit of measurement of NMES that the children could understand. Questions were included on maximum daily NMES recommendations, NMES content of a range of foods (using teaspoons of sugar), energy balance and general nutrition. Initially, the questionnaire was tested with 29 children to assess whether they understood the questions and could complete the questionnaire appropriately. The questionnaire was revised and retested in a separate group of 36 children who gave feedback; $75 \%$ thought its difficulty was about right, and they all liked the layout. With further revisions, it was retested with a new sample of 38 children. From this stage, an item difficulty index was used to assess each item on the questionnaire with 20 of the 27 questions falling within the recommended boundaries ${ }^{(4)}$. Item discrimination (testing the ability of each question to discriminate between children with varying levels of knowledge) was assessed using an item-to-total score correlation which should not fall below 0.2 for any individual question ${ }^{(5)}$. The discrimination index ranged from -0.19 to 0.59 (mean $=0.06)$. Although eight questions fell outside the discrimination or difficulty boundaries they were left in the final questionnaire as they were considered important for maintaining the appeal of the questionnaire to children. The internal consistency of the questionnaire was tested using Cronbach alpha $(\alpha)$. The whole questionnaire scored an $\alpha$ of 0.64 . When the questionnaire was divided into different areas of knowledge, i.e. (i) NMES and nutrition, (ii) energy balance and physical activity, the $\alpha$ was 0.71 and 0.41 , respectively. The questionnaire had a readability Flesh Kincaid grade level score ${ }^{(6)}$ of 5.9, deeming it suitable for children aged 10 years and above. The results suggest that the final questionnaire is a useful tool to measure knowledge on NMES and energy balance in children, an increasingly important area of nutrition and health. The reliability testing suggests that it is perhaps a more suitable tool to measure knowledge of NMES and nutrition compared to physical activity and energy balance. With excessive intakes of NMES becoming an ever more prominent issue, it is both a useful and novel tool that can be used in education programmes to help test children's knowledge on the subject.

1. Scottish Government, Health and community care. (2005). Scottish Dietary Targets for 2005. http://www.scotland.gov.uk/Topics/Health/health/19133/ 17756.

2. Sheehy C, McNeill G, Masson L et al. (2008) Survey of sugar intake among children in Scotland. http://www.food.gov.uk/multimedia/pdfs/ sugarintakescot2008rep.pdf.

3. Ludwig DS, Peterson KE \& Gortmaker (2001) Relation between consumption of sugar-sweetened drinks and childhood obesity. Lancet 357, 505-508.

4. Streiner DL \& Norman GR (1989) Health Measurement Scales: A Practical Guide to Their Development and Use. Oxford: Oxford University Press.

5. Kline P (1993) The Handbook of Psychological Testing. London: Routledge.

6. Flesch R (1948) A new readability yardstick. J Appl Psychol 32(3), 221-233. 